This item was submitted to Loughborough's Research Repository by the author.

Items in Figshare are protected by copyright, with all rights reserved, unless otherwise indicated.

\title{
The effectiveness of conceptual airport terminal designs
}

PLEASE CITE THE PUBLISHED VERSION

PUBLISHER

(C) Routledge (Taylor \& Francis)

VERSION

AM (Accepted Manuscript)

LICENCE

CC BY-NC-ND 4.0

REPOSITORY RECORD

Jones, D.R., and D.E. Pitfield. 2019. "The Effectiveness of Conceptual Airport Terminal Designs". figshare. https://hdl.handle.net/2134/4046. 
This item was submitted to Loughborough's Institutional Repository (https://dspace.lboro.ac.uk/) by the author and is made available under the following Creative Commons Licence conditions.

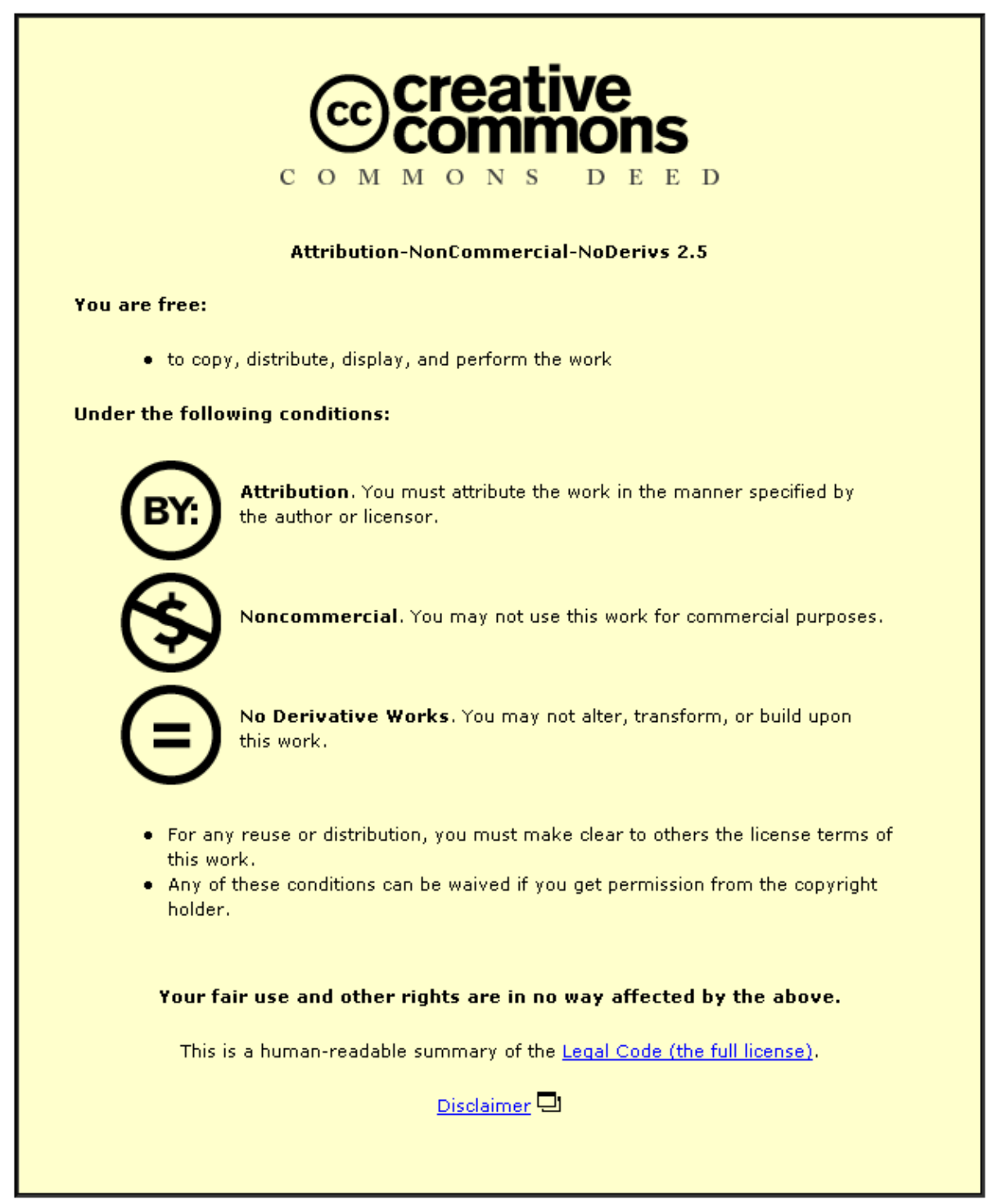

For the full text of this licence, please go to: http://creativecommons.org/licenses/by-nc-nd/2.5/ 


\title{
The Effectiveness of Conceptual Airport Terminal Designs.
}

\author{
D.R. Jones and D.E.Pitfield \\ Transport Studies Group \\ Department of Civil and Building Engineering \\ Loughborough University \\ Loughborough \\ Leicestershire LE11 3TU \\ UK \\ E-mail: D.E.Pitfield@lboro.ac.uk
}

It is forecast that there will be a large growth in air traffic over the next decade or so and to accommodate this will require investment in airport infrastructure including terminals. These buildings represent large, lumpy investments so it is important to provide the capacity to accommodate the forecast traffic. However, this depends on at least two factors; the accuracy of the forecast of future demand and the process of translating these forecasts into designs. Errors in either of these can be financially catastrophic. The latter of these two factors depend on "rules of thumb" formulae that convert design hour flows into area requirements for each terminal facility.

This paper will look in detail at the process of translating demand forecasts into conceptual terminal designs. The basic methods that are used will be outlined and how they affect the conceptual terminal design process will be revealed. It will be shown that even if demand forecasts can be taken to be completely accurate, there can still be errors in terminal design and size resulting from the use of these "rules of thumb." 


\section{Introduction}

Aviation passenger traffic is forecast to grow dramatically over the next twenty years. It is predicted that traffic at UK airports will increase from a total of $160 \mathrm{mppa}$ to $400 \mathrm{mppa}$ between 1998 and 2020 (DfT, 2000). This represents a 150\% increase in traffic. Whilst the UK government has made it clear that they do not intend to provide for all of this capacity, a recent government white paper has announced intentions for increased airport capacity across the country, including increased terminal capacity. (DfT, 2003)

To accommodate this forecast traffic, investment in infrastructure and airport passenger buildings is required and this represents large and lumpy capital investment projects for airport authorities. These projects are surrounded by a large degree of risk because of the reliability of the demand forecasts and the process of translating the demand forecasts into conceptual terminal designs. If there are errors in either of these two, then terminals can be severely under or over designed.

There are many "rules of thumb" formulae that convert design hour flows into area requirements for each terminal facility. These different formulae seem to vary considerably from country to country and even between different airport operators in the same country. (Ashford and Wright, 1992).

This paper will look in detail at the process of translating demand forecasts into conceptual terminal designs.

The next section examines the calculation of terminal design plans based on flow rates; the calculation of flow rates and the level of service. Section three examines the choice of 
airports used in the empirical analysis and applies the flow rate calculations. Section four shows how the conceptual design is calculated for three areas of the terminal and sections five and six focus on the determination of the best measure, after a number of key assumptions, by comparing suggested designs with Level of Service (LOS) outputs. Conclusions are given in section seven.

\section{Conceptual Terminal Design Calculations}

\subsection{Rules of Thumb and Busy Hour Rates}

The conceptual design phase of an airport passenger building consists of translating annual demand figures into layout plans detailing the size and functionality of each area of an airport terminal ${ }^{1}$. There are a number of ways in which this translation can be made.

The US Federal Aviation Administration's (FAA) Typical peak Hour Passengers (TPHP) method dates back to the 1950's and is widely used (Ashford and Wright 1992). It is based on an assumption that there is a standard relationship between the peak design hour and annual traffic flows. Whilst this is a valid assumption, the method does not include a valuation of dwell time, an important consideration that designers in the past have not included in their calculations. Expensive errors have resulted as requirements have been overestimated. (De Neufville and Odoni, 1992). The data for this method has been taken from Ashford and Wright (1992) and FAA (1998) and Table 2.1 shows the relationship between annual passenger throughput and Busy Hour Flows.

\footnotetext{
${ }^{1}$ Ashford and Wright (1992) identify access and landside interface, processing, holding areas, internal circulation and support activities such as airline offices and toilets as the five main functions of airport terminals
} 


\begin{tabular}{|r|c|}
\hline Total Annual Passengers & $\begin{array}{r}\text { TPHP as a percentage of } \\
\text { annual flows }\end{array}$ \\
\hline 20 Million and Over & $0.030 \%$ \\
\hline Less than 20 Million & $0.035 \%$ \\
\hline Less than 10 Million & $0.040 \%$ \\
\hline Less than 1 Million & $0.050 \%$ \\
\hline Less than 500,000 & $0.065 \%$ \\
\hline Less than 100,000 & $0.12 \%$ \\
\hline
\end{tabular}

Table 2.1:FAA Recommended Relationship between annual flows and TPHP Source: FAA (1988)

Table 2.2 demonstrates the recommended area required for each facility using the FAA method.

\begin{tabular}{|r|c|}
\hline \multicolumn{1}{|r|}{ Facility } & Required per $\mathbf{T P H P}\left(\mathbf{m}^{2}\right)$ \\
\hline Ticket Lobby & 1.0 \\
\hline Waiting Rooms & 1.8 \\
\hline Immigration & 1.0 \\
\hline
\end{tabular}

Table 2. 2:FAA Standards

Source: FAA (1988)

The British Airport Authorities (BAA) airport planning methods have been developed from the organisation's own experience of airport planning, and conceptual designs are produced based on a number of calculations, which require assumptions on factors such as the proportion of transfer traffic and the processing capacity of facilities. The calculations have been taken from BAA (1997) and two methods will be tested from the BAA guidelines, based on the Standard Busy Rate (SBR) design hour, and the $30^{\text {th }}$ busy hour, both common peak design hours used by BAA. (See De Neufville and Odoni, 2003 and Ashford et al, 1997) 
The BAA formulae used in this paper are shown in Table 2.3

\begin{tabular}{|c|c|c|}
\hline Result & Formula & Assumptions \\
\hline $\begin{array}{r}\text { Number } \\
\text { of Processing } \\
\text { Desks }\end{array}$ & $N_{d}=\frac{N_{e} \times T_{t} \times S_{f}}{3600}$ & $\begin{array}{r}\mathrm{N}_{\mathrm{d}}=\text { Number of Desks } \\
\mathrm{N}_{\mathrm{e}}=\text { Number of passengers to be } \\
\text { processed } \\
\mathrm{Tt}=\text { Transaction Time (Assume } 90 \mathrm{~s}) \\
\mathrm{S}_{\mathrm{f}}=\text { Service Factor (1.2 for economy } \\
\text { passengers) }\end{array}$ \\
\hline $\begin{array}{r}\text { Area of Check-In } \\
\text { Area }\end{array}$ & $A=D \times 0.8 \times 2$ & $\begin{array}{r}\text { A = Area of Check-In } \\
\mathrm{D}=\text { Number of Dwell Passengers } \\
\text { (Assume Dwell time is } 15 \text { minutes) } \\
0.8=\text { Service Space per passenger } \\
2=100 \% \text { Inter queue Area }\end{array}$ \\
\hline $\begin{array}{r}\text { Departures } \\
\text { Lounge }\end{array}$ & $A=\frac{D F R \times D \times P}{60}$ & $\begin{array}{r}\text { A = Area of Lounge } \\
\text { DFR = Design Flow Rate } \\
\text { D = Dwell Time (Assume } 35 \text { mins) } \\
\text { P = Peaking Factor (Assume 1.5) }\end{array}$ \\
\hline $\begin{array}{r}\text { Immigration } \\
\text { Desks (Arrivals } \\
\text { Processing) }\end{array}$ & $N_{d}=\frac{D F R \times S_{f} \times T_{t}}{3600}$ & $\begin{array}{r}\text { DFR }=\text { Design Flow Rate } \\
\mathrm{T}_{\mathrm{t}}=\text { Transaction Time (Assume } 10 \mathrm{~s} \\
\text { for UK and EU pax) } \\
\mathrm{S}_{\mathrm{f}}=\text { Service Factor (1.2 for economy } \\
\text { passengers) }\end{array}$ \\
\hline $\begin{array}{r}\text { Area } \\
\text { of Immigration }\end{array}$ & $A=D \times 0.8 \times 2$ & $\begin{array}{r}\mathrm{A}=\text { Area of Processing } \\
\mathrm{D}=\text { Number of Dwell Passengers } \\
\text { (Assume Dwell time is } 12 \text { minutes for } \\
\text { EU\& UK pax) } \\
0.6=\text { Service Space per passenger } \\
2=100 \% \text { Inter queue Area }\end{array}$ \\
\hline
\end{tabular}

Table 2. 3:Area requirement calculations

Source: BAA (1997)

Blow (1996) identifies a third set of assumptions that can be made in assessing the requirements for the number of processing desks and area for each section of the terminal. These assumptions are shown in Table 2.4. These assumptions will be used with three other busy hour flow rates (BHFR), to create three further methods in addition to the methods identified above. 


\begin{tabular}{|r|r|}
\hline \multicolumn{1}{|c|}{ Area } & Assumptions \\
\hline Check-In & Peaking Factor $=1.5$ \\
& Area per passenger $=1.6 \mathrm{~m}^{2}(\mathrm{LOS}$ C standard $)$ \\
Dwell Time $=20$ minutes \\
Transaction Time $=90 \mathrm{~s}$
\end{tabular}

Table 2. 4: Conceptual Design Assumptions

Source: Blow (1996)

\subsection{Level of Service (LOS)}

Table 2.5 demonstrates the widely accepted LOS values currently recommended by IATA (1985). These standards are based on a grading system from A - E (sometimes F is included as a measure of total system failure). The IATA criteria are based on a space per simultaneous occupant, with more space equating to a higher level of service. LOS A is the highest standard, with C being considered an acceptable average level.

\begin{tabular}{|r|r|r|r|r|r|}
\hline Level of Service & $\boldsymbol{A}$ & $\boldsymbol{B}$ & $\boldsymbol{C}$ & $\boldsymbol{D}$ & $\boldsymbol{E}$ \\
\hline Check-In & 1.8 & 1.6 & 1.4 & 1.2 & 1 \\
\hline Wait/ Circulate & 2.7 & 2.3 & 1.9 & 1.5 & 1 \\
\hline Hold Room & 1.4 & 1.2 & 1 & 0.8 & 0.6 \\
\hline Bag Claim Area & 2 & 1.8 & 1.6 & 1.4 & 1.2 \\
\hline GIS & 1.4 & 1.2 & 1 & 0.8 & 0.6 \\
\hline
\end{tabular}

Table 2.5: Level of Service Criteria, Space per simultaneous occupant, $\left(\mathrm{m}^{2}\right)$

Source: IATA (1985) 
Ashford et al (1997) suggests that a simple quantity of space per passenger is an inadequate measure of LOS as there is a relationship between space provision, the amount of time spent in a facility and the perception of service by the passengers. Further, Ashford and Wright (1992) believe that LOS perceptions are different depending on the passenger type. Nevertheless, this paper will use the IATA LOS criteria to form the basis of analysis, as these are internationally recognised and accepted standards.

\section{Airport Choice and the Calculation of Busy Hour Rates}

The timetable busy hour requires a full schedule for the airport. It calculates the passenger flows in the busiest scheduled hour based on average load factors, for example, the 95\% Busy Hour was used in the construction of the new Hong Kong International airport. (De Neufville and Odoni, 2003) and this is the hourly rate above which only 5\% of the airport traffic falls within the year. If it can be assumed that the number of hourly movements at the airport is normally distributed, then, using normal distribution tables, the number of movements that occur less than $95 \%$ of the year can be calculated. Using average passenger load factors, the 95\% busy hour can be calculated in terms of passenger flows from sample data.

It was decided to survey airports within the UK that had a passenger throughput of between 2 mppa and 4 mppa in 2002. The sample considered commercial air transport movements at the six airports shown in Table 3.1 for the average 24-hour period between $5^{\text {th }}$ and $11^{\text {th }}$ January 2003.

For each airport an average number of movements per hour, and the associated standard deviation can be calculated. Then assuming that this traffic is distributed normally, the 95\% and 98\% values can be calculated. This information is shown in Table 3.1. 


\begin{tabular}{|c|c|c|c|c|}
\hline Airport & no. of movements & $\begin{array}{c}\text { Standard } \\
\text { Deviation }\end{array}$ & $\begin{array}{r}95 \% \\
\text { Movements }\end{array}$ & $\begin{array}{r}98 \% \\
\text { Movements }\end{array}$ \\
\hline Aberdeen & 6.42 & 5.64 & 15.7 & 18.0 \\
\hline Belfast & 4.04 & 3.96 & 10.6 & 12.2 \\
\hline Bristol & 5.33 & 4.65 & 13.0 & 14.9 \\
\hline EMA & 4.46 & 3.31 & 9.9 & 11.3 \\
\hline Liverpool & 3.75 & 2.88 & 8.5 & 9.7 \\
\hline Newcastle & 4.96 & 4.16 & 11.8 & 13.5 \\
\hline & & Average & 11.6 & 13.2 \\
\hline \multicolumn{3}{|c|}{ Average Total Daily Movements } & \multicolumn{2}{|r|}{115.8} \\
\hline \multicolumn{3}{|c|}{ \%Annual Traffic } & $0.0274 \%$ & $0.0313 \%$ \\
\hline
\end{tabular}

Table 3.1: Calculating the 95\% and 98\% Busy Hour

The relationship between timetable busy hour and annual traffic is shown in Table 3.2.

\begin{tabular}{|r|r|r|}
\hline Airport & $\begin{array}{r}\text { Peak Hourly Movements: } \\
\text { Total Daily Movements }\end{array}$ & $\begin{array}{r}\text { Peak Hourly Movements: } \\
\text { Total Annual Movements }\end{array}$ \\
\hline Newcastle & $11 \%$ & $0.0299 \%$ \\
\hline Belfast & $15 \%$ & $0.0424 \%$ \\
\hline Aberdeen & $10 \%$ & $0.0285 \%$ \\
\hline Liverpool & $10 \%$ & $0.0274 \%$ \\
\hline EMA & $12 \%$ & $0.0333 \%$ \\
\hline Bristol & $11 \%$ & $0.0300 \%$ \\
\hline Average & & $0.0319 \%$ \\
\hline
\end{tabular}

Table 3.2: Relationship between Annual Traffic and Timetable busy Hour.

For the six sample airports, data was also collected showing the annual passenger throughput. The results of this survey are shown in Table 3.3. 


\begin{tabular}{|r|r|r|r|}
\hline \multirow{2}{*}{ Airport } & \multicolumn{3}{|r|}{2001 Traffic Data } \\
\cline { 2 - 4 } & Total Passengers & $\begin{array}{r}\text { Commercial Passenger } \\
\text { Movements }\end{array}$ & Pax/ATM \\
\hline Aberdeen & $2,561,000$ & 83942 & 30.51 \\
\hline Belfast & $3,621,000$ & 44228 & 81.87 \\
\hline Bristol & $2,694,000$ & 40947 & 65.79 \\
\hline EMA & $2,398,000$ & 28373 & 84.52 \\
\hline Liverpool & $2,258,000$ & 20103 & 112.32 \\
\hline Newcastle & $3,463,000$ & 41360 & 83.73 \\
\hline & & Average & 76.46 \\
\hline
\end{tabular}

Table 3.3: Traffic Data for the 6 sample airports

Source: RATI (2004), ACI (2002)

Therefore, from sample data, and published data, the relationships found between annual traffic flows and the design peak hour for airports with a passenger throughput of between 2 and 4 mppa are summarised in Table 3.4

\begin{tabular}{|r|r|}
\hline BHFR & Peak Hour : Annual Traffic (\%) \\
\hline TPHP & $0.0400 \%$ \\
\hline SBR & $0.0400-0.0430 \%$ (Depending on number of ATMs) \\
\hline $30^{\text {th }}$ Busy Hour & $y=e^{(0.857 . \log (x))-2.39}$ \\
& Where x = Annual Traffic \\
\hline 95\% Busy Hour & $0.0274 \%$ \\
\hline 98\% Busy Hour & $0.0313 \%$ \\
\hline Timetable Busy Hour & $0.0319 \%$ \\
\hline
\end{tabular}

Table 3.4: The relationship between annual traffic and busy hour flow rates 
Using the busy hour flow rates and the calculations shown above, it is possible to produce conceptual designs for certain areas of the terminal. The conceptual designs will outline the total area required for each section of the terminal, and the total number of processing facilities required.

\section{Design of Terminal Areas: Processing Arrivals and Departures and Holding Areas.}

The airport terminal will be broadly split into three areas, a departure processing function (such as Check-in or security), a holding area (such as a departure lounge) and an arrival processing area (such as immigration or customs). The reason that arrival and departure processing areas have been separated is that the number of passengers entering an arrival processing area will be more stepped than a departures processing area. For example, departing passengers will arrive at the airport at any time between three hours and 30 minutes before the scheduled time of departure, whereas the passengers from an arriving flight will arrive at the arrival processing area all within 5 or 10 minutes of each other. Thus the processing at the arrivals end of the terminal will suffer more acutely from the peak-loading problem. These areas will be the focus of the LOS analysis.

Calculations have been made to produce conceptual designs for a processing, holding and arrivals processing area that will match the traffic for each of the sample airports, using each of the six methods. To demonstrate the methodology, example 1 below shows the conceptual design for an arrivals processing area at Nottingham East Midlands airport and this process is replicated for the other airports and other design areas. 


\begin{tabular}{|c|c|c|c|c|c|c|}
\hline & & & & & & Exam \\
\hline Method & $S B R$ & $30^{\text {th }} \mathrm{BH}$ & ТPHP & Timetable & $95 \%$ & $98 \%$ \\
\hline BHFR & 1297 & 1541 & 1622 & 1035 & 888 & 1016 \\
\hline Departure BHFR & 648.5 & 770.5 & 811 & 517.5 & 444 & 508 \\
\hline Dwell Time (Hrs) & 0.25 & 0.25 & N/A & 0.33 & 0.33 & 0.33 \\
\hline $\begin{array}{r}\text { Service / Peaking } \\
\text { Factor }\end{array}$ & 1.1 & 1.1 & N/A & 1.5 & 1.5 & 1.5 \\
\hline $\begin{array}{r}\text { Space } \\
\text { per person }\end{array}$ & $0.8 \mathrm{~m}^{2}$ & $0.8 \mathrm{~m}^{2}$ & $1 m^{2}$ & $1.6 \mathrm{~m}^{2}$ & $1.6 \mathrm{~m}^{2}$ & $1.6 \mathrm{~m}^{2}$ \\
\hline Service Time & $90 \mathrm{~s}$ & $90 \mathrm{~s}$ & $90 \mathrm{~s}$ & $90 \mathrm{~s}$ & $90 \mathrm{~s}$ & $90 \mathrm{~s}$ \\
\hline Dwell Pax ${ }^{*}$ & 178 & 212 & N/A & 259 & 222 & 254 \\
\hline Area & $285 m^{2}$ & $339 m^{2}$ & $811 m^{2}$ & $414 m^{2}$ & $355 m^{2}$ & $406 \mathrm{~m}^{2}$ \\
\hline Desks & 18 & 21 & 20 & 19 & 17 & 19 \\
\hline \multicolumn{7}{|c|}{ Table 4.1: Designing the Check-In area at EMA } \\
\hline
\end{tabular}

The method chosen to assess these designs is to test a number of existing airport schedules against these prescribed areas to see which gives the best results.

Schedules derived from OAG data (OAG, 2002) will be taken for Bristol, Liverpool, Newcastle and Nottingham East Midlands airport where a schedule including charter traffic for 2003 will also be used for comparisons (EMA, 2003). Based on a set of assumptions, such as the time it takes to process a passenger in each facility area, the model will assess for each five-minute segment of the day, the number of passengers entering the facility, and the number of passengers leaving the facility. If the number of passengers entering the facility is 
greater than the number of passengers leaving the facility, then there will be a number of passengers that will remain in the area and form a queue. The model will then calculate the area available per remaining passenger for each sector of the day, and based on the level of service standards shown in Table 2.5, determine the number of 5-minute segments that operate at each level of service standard in each week. The model will have a filter to show differences in traffic profiles between different days of the week.

Table 4.2 shows the airport schedules that will be input into the model:

\begin{tabular}{|l|c|}
\hline \multicolumn{1}{|c|}{ Airport } & Annual Traffic (2002 unless otherwise stated) \\
\hline Bristol & $3,445,945$ \\
\hline $\begin{array}{l}\text { Nottingham East Midlands } \\
\text { Airport }\end{array}$ & $3,243,000$ \\
\hline $\begin{array}{l}\text { Nottingham East Midlands } \\
\text { Airport (2003 Full } \\
\text { Schedule) }\end{array}$ & $4,411,021$ \\
\hline Liverpool & $2,839,442$ \\
\hline Newcastle & $3,458,845$ \\
\hline Best Case & $3,267,264$ \\
\hline Worst Case & $3,494,400$ \\
\hline
\end{tabular}

Table 4.2: Airport Schedules to be tested

Source: Traffic Data (ACI, 2003), Schedules (OAG, 2002) and (EMA, 2003)

\subsection{Measuring LOS}

After considerable thought it was decided to measure the total number of $\mathrm{B}, \mathrm{C}$ and $\mathrm{D}$ segments minus the number of E segments per week and divide this by the cost of the facility. It was chosen to measure B, C, and D segments as these are deemed to be acceptable level of service standards. (Ashford et al, 1997) The number of LOS E segments would be deducted from this number, to identify terminals that had been under designed. A negative value at this 
point would signify a severely under designed terminal, where it operates at a failed level of service for more periods of the week than it operates at an acceptable level of service.

\subsection{Costs}

In order to compare terminals the number of BCD - E segments in the day is divided by the overall cost of the facility.

The cost data used in the assessment in shown in Table 4.3.

\begin{tabular}{|l|l|}
\hline \multicolumn{1}{|c|}{ Facility } & Cost (£) \\
\hline Airport Terminal $\left(\right.$ per $\mathrm{m}^{2}$ ) & $£ 1,800$ \\
\hline Check-In Processing Facility & $£ 2,000$ \\
\hline Immigration Processing Facility & $£ 2,000$ \\
\hline
\end{tabular}

Table 4.3: Cost Estimates for airport facilities

Source: (Davies et al, 2000)

These costs are only a simple estimation, and it is known that cost of construction for airport terminals can vary considerably depending on the location of the airport. (Davies et al, 2000). However, it is included here simply as a guideline to compare the LOS of a terminal to its overall size and processing capacity.

\section{Key Assumptions of the Model and Validation}

\subsection{Load Factor}

When testing terminal LOS performance against existing airport schedules, the passenger load factor of aircraft using the airport is essential, as this will determine the number of passengers using the terminal. It is possible that the load factor will vary depending on the airline, the time of day and day of the week of the flight, and many other factors. It would be possible to include an option to change the load factor for every flight, or to use an average 
load factor for each day of the week, however, for simplicity it was determined best to use one average load factor for all of the flights in the schedule. This is a reasonable assumption because traditional airlines have load factor targets, which they aim to achieve by changing the price of tickets before the aircraft departs. (Hanlon, 1999)

The first method used to estimate load factors is the "seat used method". This method compares the total number of passengers travelling through the airport in the year with the total number of scheduled seats available from the airport in that year. The main problem with this method is that the OAG guide only provides information on scheduled departure flights. However, the annual passenger traffic will include charter passenger traffic and this will not be included in the OAG guide. Therefore, it is quite possible for this method of estimating load factor to estimate that aircraft using the airport operate at a load factor greater than $100 \%$. This will therefore have the effect of exaggerating the peak periods, and making the conceptual terminal designs appear to perform worse than they would if the full schedule is input into the model. This method will be used to estimate the load factor with the full Nottingham East Midlands airport schedule (where charter traffic is included), and for comparison purposes, a model run will be made using this load factor method with the other schedules.

The second method used to estimate load factor, is less exact, but is more likely to give a realistic estimation than using the "seat used" method identified above. The second method chosen to estimate load factor is to identify the top three scheduled carriers at the airport, in terms of number of flights per week, and then find a weighted average of the published load factors of these airlines. Table 5.1 and 5.2 identifies the load factors that will be used in the model runs. 


\begin{tabular}{|l|c|c|c|}
\hline \multicolumn{1}{|c|}{ Airport } & Departing Pax & $\begin{array}{c}\text { Scheduled** } \\
\text { Departure Seats }\end{array}$ & Load Factor \\
\hline Bristol & $1,722,973$ & 792,020 & $136 \%$ \\
\hline EMA & $1,621,500$ & $1,517,516$ & $107 \%$ \\
\hline EMA Full & $1,485,346$ & $2,190,461$ & $68 \%$ \\
\hline Liverpool & $1,419,721$ & $1,101,828$ & $129 \%$ \\
\hline Newcastle & $1,729,423$ & 762,020 & $227 \%$ \\
\hline
\end{tabular}

Table 5.1: Seat Used Method of Calculating Load Factor

* The number of departing passengers is calculated based on the assumption that $50 \%$ of the total passenger traffic at the airport is departing traffic. This is not strictly true as people often start and end their journey at different airports. However, without further information, and assuming that at smaller airports transfer traffic and migrating traffic will be negligible, then this is a reasonable assumption. Source: RATI (2004)

** Source: OAG (2002)

\begin{tabular}{|c|c|c|c|}
\hline Airport & Carrier & Weekly Frequency & Load Factor* \\
\hline \multirow{4}{*}{ Bristol } & $\mathrm{BE}$ & 12 & $60.2 \%$ \\
\hline & GO & 26 & $85.5 \%$ \\
\hline & BA & 44 & $71.9 \%$ \\
\hline & \multicolumn{2}{|r|}{ Weighted Average } & $75 \%$ \\
\hline \multirow{4}{*}{ EMA } & GO & 8 & $85.5 \%$ \\
\hline & WW & 28 & N/A \\
\hline & $\mathrm{BD}$ & 44 & $68.6 \%$ \\
\hline & \multicolumn{2}{|r|}{ Weighted Average } & $71 \%$ \\
\hline \multirow{4}{*}{ Liverpool } & $\mathrm{U} 2$ & 52 & $85 \%$ \\
\hline & FR & 5 & $84 \%$ \\
\hline & $\mathrm{JE}$ & 15 & $\mathrm{~N} / \mathrm{A}$ \\
\hline & \multicolumn{2}{|r|}{ Weighted Average } & $85 \%$ \\
\hline \multirow{4}{*}{ Newcastle } & BA & 42 & $71.9 \%$ \\
\hline & UK & 7 & $71 \%$ \\
\hline & $\mathrm{BE}$ & 16 & 60.2 \\
\hline & \multicolumn{2}{|r|}{ Weighted Average } & $69 \%$ \\
\hline
\end{tabular}

Table 5.2: Sample Method of Calculating Load Factor

*Source: RATI (2004) 


\subsection{Passenger Arrival Times}

There are very few occasions that all passengers on a departing flight will arrive at the terminal at the same time. (The only real example of this is when passengers on charter flights are bussed to the airport together). Generally, for scheduled departure flights, passengers will arrive at the airport in a gradual process. The destination type (international or domestic), flight type (charter or scheduled) and ticket type (restricted or unrestricted) will all affect the pattern in which passengers arrive at the airport. For example, international passengers with restricted tickets are more likely to arrive early at the airport, whereas passengers on domestic flights with unrestricted tickets are more likely to arrive at the airport closer to the departure time. (Ashford et al, 1997) Therefore, the passenger arrival pattern at the airport is dictated by the consequences for the passenger of missing the flight. Clearly there will be higher consequences (including having to buy a new ticket or waiting until the next day to travel) for a passenger with a restricted non-refundable ticket travelling on an international flight. (Ashford et al, 1997)

The model will consider the different arrival patterns at the airport for domestic and international passengers. IATA (1985) recommends that detailed surveys should be conducted in order to assess arrival patterns of different passenger types at the airport. However, as this information is not available, the initial guideline figures provided by IATA (1985) will be used. These are shown below in Table 5.3. 


\begin{tabular}{|c|c|c|c|c|c|c|c|c|c|}
\hline Flight Type & \multicolumn{7}{|c|}{ Time Before Departure } \\
\hline International & $02: 30$ & $02: 15$ & $02: 00$ & $01: 45$ & $01: 30$ & $01: 15$ & $01: 00$ & $00: 45$ & $00: 30$ \\
\hline Domestic & $01: 40$ & $01: 30$ & $01: 20$ & $01: 10$ & $01: 00$ & $00: 50$ & $00: 40$ & $00: 30$ & $00: 20$ \\
\hline \% Pax & $1 \%$ & $2 \%$ & $6 \%$ & $10 \%$ & $20 \%$ & $25 \%$ & $20 \%$ & $12 \%$ & $4 \%$ \\
\hline
\end{tabular}

Table 5.3: Passenger Arrival Patterns at the airport

Source: IATA (1985)

Figure 5.1: Cumulative Passenger Arrival Patterns

Source: IATA (1985)

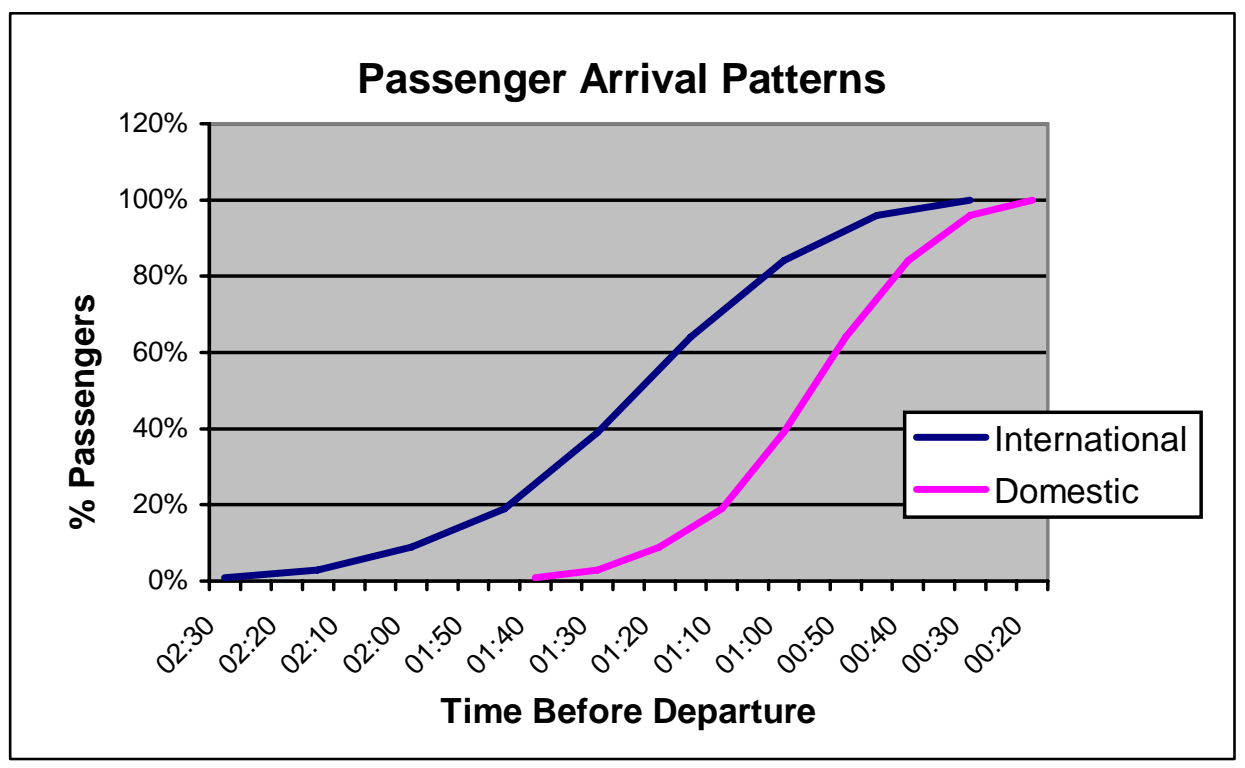

5.4 Seats per Aircraft

The OAG flight guide identifies the aircraft type associated with each flight from the airport.

However, the total number of seats provided on that aircraft will depend on the internal configuration of the aircraft. A Boeing 737 operated by a full fare airline on a high yield business route is likely to have fewer seats than the same aircraft type operated by a low cost carrier on leisure routes. (Doganis, 2001) The full schedule for Nottingham East Midlands Airport (EMA) provides an easy solution to this problem, in that the number of seats offered on each flight is published. However, for the other OAG schedules, it has been decided to use 
the published figure of “Typical Maximum” configuration for each aircraft type. (RATI, 2004)

\subsection{Boarding Times}

In order to model passenger traffic through a departure lounge, it is necessary to know the time before the scheduled time of departure the aircraft will start to board. This will depend on the airport characteristics (size, ease of finding gate), aircraft size and airline operating procedures. For simplicity, it has been assumed that boarding time is proportional to aircraft size.

\subsection{Passenger Flow into the Departure Lounge}

In order to assess the LOS provided by the departure lounge, two further pieces of information are required: the passenger arrival profiles into the departure lounge and the time it takes for one passenger to board the aircraft.

The passenger arrival pattern into the departure lounge is assumed to be identical to the passenger arrival pattern at the airport. This is a reasonable assumption, but it does assume that the passengers will not be held up at a previous processing station, such as check-in or security. In practice, the flow of passengers into the departure lounge will be regulated by security and check-in processing capacity, as delays encountered at these processing stations will provide a steady flow of passengers into the departure lounge. However, for simplicity the model will assume that passengers arrive into the departure lounge in the same pattern that they arrived at the airport. 


\subsection{Processing Times}

Another piece of information required is the time it takes for one passenger to board. As with all processing times, this can vary to a large degree depending on passenger characteristics (elderly and disabled passengers may take longer to board than other passenger types), airline procedures, and flight type. However, for the purpose of this paper, the time taken for one passenger to board a flight will be taken as 5 seconds (for all passengers), taken from Horonjeff and McKelvey (1994).

One of the assumptions made for the designs and for the analysis of these terminal designs, is that the processing time at check-in is 90 seconds. However, Wells (2000) points out that average check-in times at airports around the world can range from $1.4-5.6$ mins. It may be better for the terminal designer to consider a range of check-in times, and vary these in the simulation model to see how they affect the outcome. However, this paper has chosen to use 90 seconds as a processing time, the suggested time used by BAA (1997) in their calculations.

An additional assumption in modelling the check-in area is that passengers will only spend time in that area when they are being processed i.e. they do not dwell in that area for longer than it takes them to be processed. In reality, this may not be completely true, as passengers may spend time with friends and relatives in this area in addition to the time taken for processing.

\subsection{Passengers Accompanying Friends and Relatives}

One of the problems associated with terminal planning is encountered when considering landside concourses. Many methods of terminal design consider only the number of 
passengers that the terminal will process. However, in the landside concourses of the terminal the passenger may be accompanied by a number of friends and relatives. The number of friends and relatives will depend on the passenger and flight type, and will directly influence the level of service in these areas (Ahyudanari, 2001). Because of a lack of available information on the number of people accompanying passengers, this paper will only consider passengers within each of the design areas. Whilst this gives an indication of level of service in each area, the reader should be aware that terminals that appear over designed may perform better in the model if the number of friends and relatives accompanying the passenger is also taken into consideration

\subsection{Delay}

The simulation model considers only a perfect schedule; that is, a schedule that is free from delay. Such a schedule, of course, is completely unrealistic, but it is difficult to model delay as it is unpredictable in nature and so it was decided that all delays should be ignored.

\subsection{Model Validation}

It was important to make sure that the output from the model coincided with what would logically be expected to ensure that conclusions based on the model output are valid. Therefore two "imaginary" schedules were created based on a traffic profile of approximately 3 mppa. The first schedule was a best-case scenario, where the traffic was distributed evenly over 17 hours per day and 7 days a week. The hourly flows through the terminal were thus average hourly flows, and any terminal design designed for the peak hour should over estimate the area required to process the passengers. 
The second schedule, the worst-case scenario was designed based on the same level of traffic, 3mppa, distributed in a much "peakier" manner. The schedule assumed that the traffic was spread over six operational hours per day, (a morning and evening peak) and over five days a week. It is therefore expected that all of the terminal designs would perform poorly in the schedule analysis test.

In reality both of the schedules are highly unlikely, but an airport such as London Heathrow, would experience a traffic profile similar to the best-case schedule, with traffic spread evenly throughout the day. London City airport caters for a specialist niche business passenger market, and is likely to experience a traffic profile similar to the worst-case scenario. (Ashford et al, 1997)

The hypothetical timetables were a good method of not only testing that the model output was consistent with the input, but also a good check that the BCD - E measure was a good measurement to take.

\section{Best Terminal Designs: The Results}

For simplicity, methods will be referred to by number throughout this section. The method associated with each number is shown below.

\begin{tabular}{|c|l|}
\hline Number & \multicolumn{1}{|c|}{ Method } \\
\hline 1 & BAA Calculations using the Standard Busy Rate Hour (SBR) \\
\hline 2 & BAA Calculations using the $30^{\text {th }}$ Busy Hour \\
\hline 3 & FAA Calculations using the TPHP Busy Hour \\
\hline 4 & Blow (1996) Calculations using the Timetable Busy Hour \\
\hline 5 & Blow (1996) Calculations using the 95\% Busy Hour \\
\hline 6 & Blow (1996) Calculations using the 98\% Busy Hour \\
\hline
\end{tabular}


The number of useful BCD-E segments per week can be translated into a useful time per year, based on the fact that one segment is equal to 5 minutes. The useful time will then be divided by the cost of the facility to give a figure for the amount of useful time produced by the facility per year per $£ 100$ of capital invested.

\subsection{Departure Processing Area}

The results in Table 6.1 and Figure 6.1 show that the TPHP method completely over designs the processing areas, as no useful time is generated. The results show that methods 1,5 and 6 (the SBR method, the 95\% and 98\% method) generate the highest results, with the best results generated by method 6 , the $98 \%$ method, which on average provides 31 seconds of useful operating time per year per $£ 100$ invested. These results are based on the seat available method of estimating average load factors as only this method generated useful time when designing the processing area ${ }^{2}$.

\footnotetext{
${ }^{2}$ The results for Newcastle airport results seemed to show that all methods underestimated the departure processing area required in the terminal. However, on closer inspection, it can be seen that a large proportion of traffic at the airport is charter traffic, and in order to calculate calculate the correct number of passengers going through the airport, the load factor used was $227 \%$ (because only scheduled departures are considered). Therefore it was assumed that every scheduled departure from the airport had a load factor of $227 \%$, and so the results from Newcastle are highly unrealistic. It was therefore decided to ignore these values when calculating the overall averages.
} 


\begin{tabular}{|c|c|c|c|c|c|c|c|c|c|c|c|c|}
\hline $\begin{array}{c}\text { Seat Available } \\
\text { Method }\end{array}$ & \multicolumn{6}{|c|}{ BCD - E Segments Per Week } & \multicolumn{6}{|c|}{ Cost of the Facility } \\
\hline Method & SBR & $\begin{array}{l}30^{\text {th }} \\
\text { BH }\end{array}$ & ТРНP & $\begin{array}{c}\text { T/Tble } \\
\text { BH }\end{array}$ & $95 \%$ & $98 \%$ & SBR & $30^{\text {th }} \mathrm{BH}$ & ТРНP & $\begin{array}{c}\text { Time Table } \\
\text { BH }\end{array}$ & $95 \%$ & $98 \%$ \\
\hline BRS & 33 & 6 & 0 & 16 & 29 & 49 & $£ 551,489$ & $£ 686,871$ & $£ 1,594,700$ & $£ 833,522$ & $£ 715,074$ & $£ 817,477$ \\
\hline LPL & 0 & 0 & 0 & 0 & 0 & 0 & $£ 481,860$ & $£ 582,543$ & $£ 1,313,749$ & $£ 686,200$ & $£ 589,545$ & $£ 674,627$ \\
\hline EMA & 19 & 5 & 0 & 10 & 18 & 10 & $£ 549,796$ & $£ 652,261$ & $£ 1,499,350$ & $£ 782,894$ & $£ 673,071$ & $£ 769,676$ \\
\hline EMA Full & -11 & 5 & 0 & 7 & 8 & 7 & $£ 674,350$ & $£ 850,433$ & $£ 2,040,959$ & $£ 1,065,180$ & $£ 915,243$ & $£ 1,047,202$ \\
\hline NCL & -725 & 64 & 8 & 120 & -559 & 62 & $£ 553,411$ & $£ 688,925$ & $£ 1,600,480$ & $£ 836,472$ & $£ 717,606$ & $£ 820,375$ \\
\hline Avg NOT NCL & 10.25 & 4 & 0 & 8.25 & 13.75 & 16.5 & $£ 692,207$ & $£ 1,609,848$ & $£ 840,854$ & $£ 722,108$ & $£ 825,871$ & $£ 692,207$ \\
\hline $\begin{array}{r}\text { Useful time per } \\
\text { £100 per year (s) }\end{array}$ & 28.44 & 9.00 & 0.00 & 15.31 & 29.70 & 31.17 & & & & & & \\
\hline
\end{tabular}

Table 6.1: Departure Processing Area - Best Method 
Figure 6.1: Departure Processing Area: Best Method

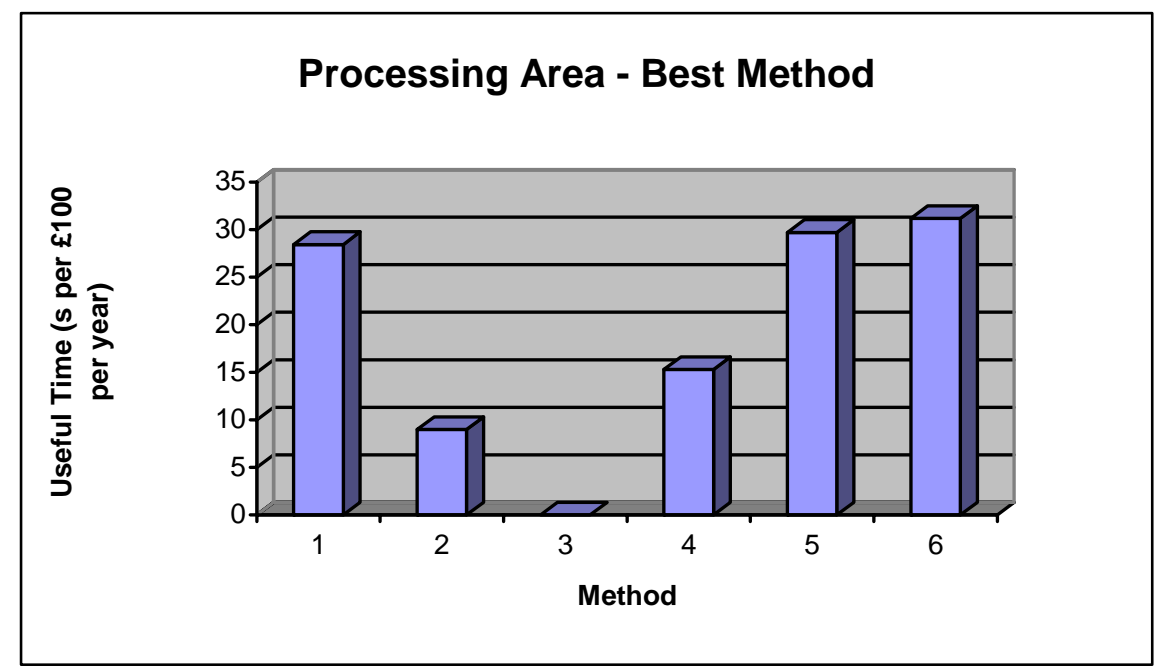

\subsection{Holding Areas}

When designing the holding areas, the TPHP method does generate some good results, however, again, the method over designs the holding areas so that that the useful time generated by the method is smaller than any other method. From Figure 6.2 it can be seen that method 4 (Timetable busy hour) gives the best results closely followed by method 6 (98\% busy hour). These results are based on an average of the two load factor methods. 


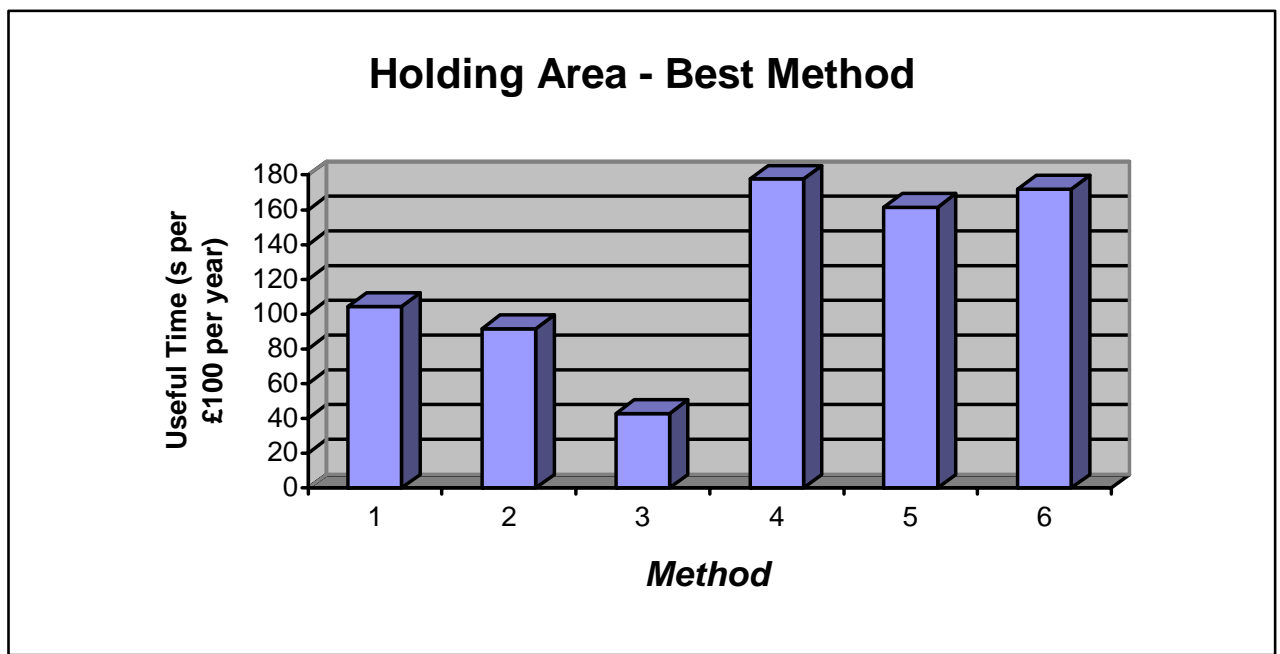

Figure 6.2: Holding Area: Best Method 


\begin{tabular}{|c|c|c|c|c|c|c|c|c|c|c|c|c|}
\hline \multirow{2}{*}{$\begin{array}{c}\begin{array}{c}\text { Seat Available } \\
\text { Method }\end{array} \\
\text { Method } \\
\end{array}$} & \multicolumn{6}{|c|}{ BCD - E Segments Per Week } & \multicolumn{6}{|c|}{ Cost of the Facility } \\
\hline & SBR & $30^{\text {th }} \mathrm{BH}$ & ТРНP & $\begin{array}{c}\text { T/Table } \\
\text { BH }\end{array}$ & $95 \%$ & $98 \%$ & SBR & $30^{\text {th }} \mathrm{BH}$ & ТPHP & $\begin{array}{c}\text { Time Table } \\
\text { BH }\end{array}$ & $95 \%$ & $98 \%$ \\
\hline BRS & 148 & 252 & 223 & 114 & -86 & 94 & $£ 1,640,193$ & $£ 2,045,499$ & $£ 2,791,260$ & $£ 1,127,919$ & $£ 967,681$ & $£ 1,107,904$ \\
\hline LPL & 245 & 136 & 39 & 347 & 318 & 361 & $£ 1,431,371$ & $£ 1,732,636$ & $£ 2,299,948$ & $£ 929,385$ & $£ 797,352$ & $£ 1,431,371$ \\
\hline EMA & 105 & 98 & 70 & 177 & 141 & 162 & $£ 1,634,806$ & $£ 1,941,740$ & $£ 2,626,830$ & $£ 1,061,474$ & $£ 910,676$ & $£ 1,042,639$ \\
\hline EMA Full & 37 & 11 & 1 & 92 & 153 & 101 & $£ 1,431,371$ & $£ 1,732,636$ & $£ 2,299,948$ & $£ 929,385$ & $£ 797,352$ & $£ 912,893$ \\
\hline NCL & 214 & 527 & 380 & -346 & -563 & -389 & $£ 1,646,307$ & $£ 2,052,035$ & $£ 2,801,664$ & $£ 1,132,123$ & $£ 971,288$ & $£ 1,112,034$ \\
\hline Avg & 149.8 & 204.8 & 142.6 & 76.8 & -7.4 & 65.8 & $£ 1,592,258$ & $£ 1,927,413$ & $£ 2,606,363$ & $£ 1,053,204$ & $£ 903,580$ & $£ 1,120,928$ \\
\hline \multicolumn{7}{|c|}{ Sample Method } & & & & & & \\
\hline BRS & 139 & 37 & 0 & 277 & 247 & 279 & & & & & & \\
\hline LPL & 42 & 14 & 0 & 207 & 296 & 274 & & & & & & \\
\hline EMA & 72 & 37 & 1 & 127 & 123 & 124 & & & & & & \\
\hline NCL & 0 & 0 & 0 & 41 & 112 & 48 & & & & & & \\
\hline Avg & 63.25 & 22 & 0.25 & 163 & 194.5 & \begin{tabular}{|l|}
181.25 \\
\end{tabular} & & & & & & \\
\hline $\begin{array}{r}\text { Useful Time } \\
\text { (Seat Avl) }\end{array}$ & 147 & 166 & 85 & 114 & -13 & 92 & & & & & & \\
\hline $\begin{array}{r}\text { Useful Time } \\
\text { (Sample) }\end{array}$ & 62 & 18 & 0 & 241 & 336 & 252 & & & & & & \\
\hline $\begin{array}{r}\text { Useful time Avg } \\
\text { per } £ 100 \text { per year } \\
\text { (s) }\end{array}$ & 104.37 & 91.78 & 42.75 & 177.60 & 161.51 & 171.91 & & & & & & \\
\hline
\end{tabular}

Table 6.2: Holding Area: Best Method 


\subsection{Arrivals Processing}

The results show that the TPHP method tends to over design the area, although not as much as it does with other areas. Methods 1, 4, 5, and 6 (SBR, Timetable Busy Hour, 95\% and 98\% Busy hour respectively) all under design the arrivals processing area. Method 2, the $30^{\text {th }}$ Busy Hour method, produces the best results.

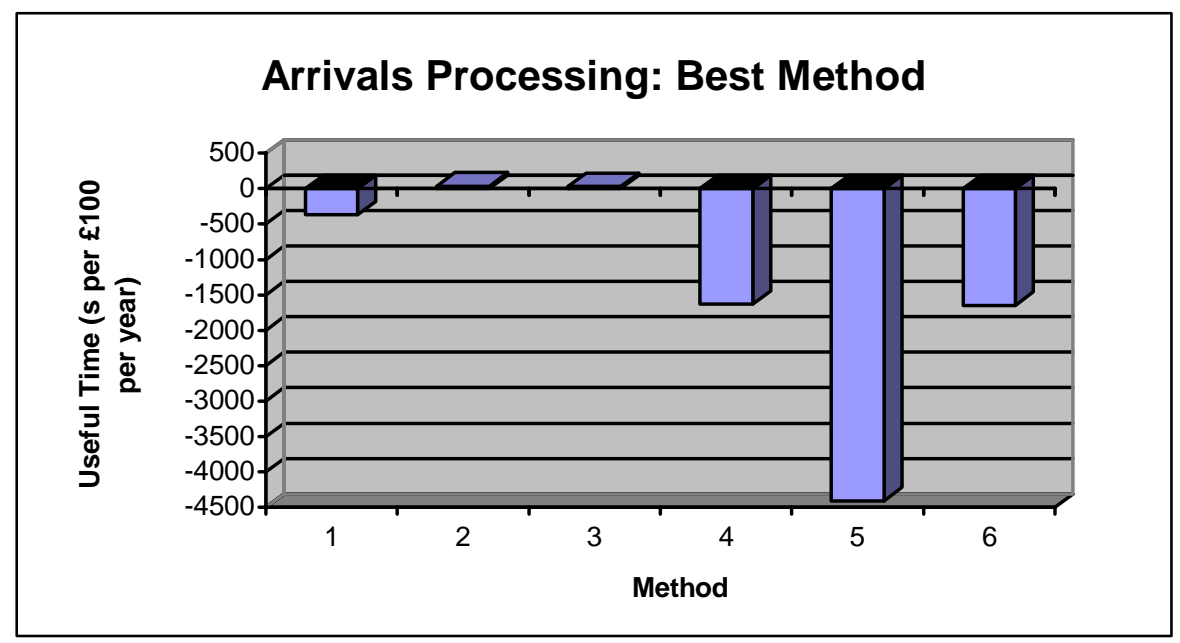

Figure 6.3: Arrivals Processing: Best Method 


\begin{tabular}{|c|c|c|c|c|c|c|c|c|c|c|c|c|}
\hline \multirow{2}{*}{\begin{tabular}{|c|}
$\begin{array}{c}\text { Seat Available } \\
\text { Method }\end{array}$ \\
Method \\
\end{tabular}} & \multicolumn{6}{|c|}{ BCD - E Segments Per Week } & \multicolumn{6}{|c|}{ Cost of the Facility } \\
\hline & SBR & $\mathbf{3 0}^{\text {th }} \mathrm{BH}$ & ТРНР & $\begin{array}{l}\text { T/Table } \\
\text { BH }\end{array}$ & $95 \%$ & $98 \%$ & SBR & $30^{\text {th }} \mathbf{B H}$ & TPHP & me Table BH & $95 \%$ & $98 \%$ \\
\hline BRS & -244 & 85 & 21 & -503 & -1343 & -503 & $£ 341,406$ & $£ 426,783$ & $£ 1,554,675$ & $£ 184,000$ & $£ 92,000$ & $£ 184,000$ \\
\hline LPL & 74 & 67 & 0 & -964 & -964 & -964 & $£ 298,454$ & $£ 360,428$ & $£ 1,281,749$ & $£ 92,000$ & $£ 92,000$ & $£ 92,000$ \\
\hline EMA & -59 & 4 & 10 & -95 & -882 & -95 & $£ 340,303$ & $£ 405,444$ & $£ 1,463,350$ & $£ 184,000$ & $£ 92,000$ & $£ 184,000$ \\
\hline EMA Full & -39 & -12 & 0 & -54 & -54 & -54 & $£ 169,585$ & $£ 204,016$ & $£ 715,861$ & $£ 53,000$ & $£ 53,000$ & $£ 53,000$ \\
\hline NCL & -1071 & -47 & 263 & -1167 & -1421 & -1167 & $£ 342,669$ & $£ 428,133$ & $£ 1,560,480$ & $£ 184,000$ & $£ 92,000$ & $£ 184,000$ \\
\hline Avg & -267.8 & 19.4 & 58.8 & -556.6 & -932.8 & -556.6 & $£ 527,348$ & $£ 647,456$ & $£ 1,565,774$ & $£ 305,989$ & $£ 233,022$ & $£ 302,621$ \\
\hline \multicolumn{7}{|c|}{ Sample Method } & & & & & & \\
\hline BRS & 22 & 11 & 0 & 33 & -687 & 33 & & & & & & \\
\hline LPL & 52 & 12 & 0 & -377 & -377 & -377 & & & & & & \\
\hline EMA & -14 & 13 & 0 & -17 & -347 & -17 & & & & & & \\
\hline NCL & 2 & 0 & 0 & 26 & -124 & 26 & & & & & & \\
\hline Avg & 15.5 & 9 & 0 & -83.75 & 383.75 & -83.75 & & & & & & \\
\hline Useful Time 1 & -792.21 & 46.74 & 58.58 & $-2,838$ & $-6,245$ & $-2,870$ & & & & & & \\
\hline Useful Time 2 & 45.85 & 21.68 & 0.00 & -426.98 & $-2,569$ & -431.73 & & & & & & \\
\hline $\begin{array}{l}\text { Useful time Avg } \\
\text { per } £ 100 \text { per year }\end{array}$ & -373.18 & 34.21 & 29.29 & $-1,632$ & $-4,407$ & $-1,650$ & & & & & & \\
\hline
\end{tabular}




\subsection{Overview}

The results show that there is no one best method of producing airport terminal conceptual designs. Different methods produce better results depending on the type of area that is designed.

In addition, it can be seen that by changing some of the model assumptions, such as the assumed load factor, the method that produces the best results can be affected. For example, consider the results for the holding area, where it was concluded that method 6 gave good results. This was a conclusion based on the average of the results from two different model runs that were identical, except for the load factor used. Table 6.4 shows the difference in useful time per $£ 100$ invested for the EMA (2002 OAG) schedule using the two different load factors. As can be seen, there is very little similarity in the performance of the methods.

\begin{tabular}{|r|c|c|c|c|c|c|}
\hline Method & $\mathbf{1}$ & $\mathbf{2}$ & $\mathbf{3}$ & $\mathbf{4}$ & $\mathbf{5}$ & $\mathbf{6}$ \\
\hline $\begin{array}{r}\text { Useful Time } \\
\text { (Seat Avl) }\end{array}$ & 147 & 166 & 85 & 114 & -13 & 92 \\
\hline $\begin{array}{r}\text { Useful Time } \\
\text { (Sample) }\end{array}$ & 62 & 18 & 0 & 241 & 336 & 252 \\
\hline
\end{tabular}

Table 6.4: Comparison between different load factors

It is not possible to conclude that there is one method that is better than any of the others for designing the whole of the airport terminal. However, some methods do consistently perform better than others, on average, such as method 6 , which is based on sample data from a selection of similar airports rather than method 3, which consistently performs badly.

Table 6.5 below summaries the results and shows how each method performs (in rank order) for each different area of the terminal. The best overall method is based on the average rank 
for each method. This conclusion is based on the assumptions stated above and the results from the schedules input into the model.

\begin{tabular}{|c|c|c|c|c|}
\hline Method & Processing Area & Holding Area & Arrivals Area & Average \\
\hline 1 & 3 & 4 & 3 & 3.33 \\
\hline 2 & 5 & 5 & 1 & 3.67 \\
\hline 3 & 6 & 6 & 2 & 4.67 \\
\hline 4 & 4 & 1 & 4 & 3 \\
\hline 5 & 2 & 3 & 6 & 3.67 \\
\hline 6 & 1 & 2 & 5 & 2.67 \\
\hline
\end{tabular}

\begin{tabular}{|c|l|l|l|l|l|l|}
\hline Rank & 1 & 2 & 3 & 3 & 3 & 6 \\
\hline Method & 6 & 4 & 1 & 2 & 5 & 3 \\
\hline
\end{tabular}

Table 6.5: Finding the Best Overall Method

Whilst it is clear from the individual results shown above there is no one best method, it is clear that consistently good results are produced by method 6 .

\section{Conclusions}

The results demonstrate that the FAA's TPHP method consistently over designs terminal areas. Even with the incorporation of additional factors such as delays and friends and relatives accompanying passengers it is likely that the terminals designed by this method would be bigger than necessary to provide the most economic solution. These results fit in with the comments made in various publications. De Neufville and Odoni (1992) state that the FAA TPHP method does not consider the dwell time of occupants. LOS criteria are based on the number of simultaneous occupants, so if passenger dwell time in a particular area is 20 minutes on average, then the design only needs to cater for $1 / 3$ of the total hourly demand. Therefore, in the majority of terminal areas designed by the TPHP method, where dwell time 
is likely to be considerably less than one hour, then the area will bigger than necessary for the number of simultaneous occupants. Ashford and Wright (1992) also argue that many airport terminals in the USA are designed on a grander scale than their European counterparts for reasons of prestige.

There are a wide range of "rule of thumb" calculations and estimations available. It is clear that standard formulae are an inadequate method of devising area requirements alone, however they do provide a starting point. Some of these methods prove better than others, in particular method 6 (the 98\% busy hour). This may be because the method is based on sample data from similar airports, or because the method considers dwell time, whereas the FAA’s TPHP method does not.

If these methods can provide an initial conceptual terminal design for planners this should be followed by an investigation of "what if" scenarios to investigate the effect of changing traffic patterns on terminal performance. Although these simple calculation methods cannot provide an exact answer to the amount of space required by an airport terminal, they can provide initial estimates and then by testing the terminal under different traffic conditions, the designer can identify the design that will provide the best performance, under the most likely range of circumstances that the stakeholders have identified. For this reason it is essential that the terminal is designed with flexibility in mind, so that areas in the terminal can be altered or redesigned in a simple and cost effective manner. 


\section{References}

ACI (2003), 2002 ACI Worldwide Traffic Report, Airports Council International, Geneva.

ACI (2002), 2001 ACI Worldwide Traffic Report, Airports Council International, Geneva.

Ahyudanari, E. (2001), Space Requirements at Airport Check-In, MSc. Thesis, University of New South Wales.

Ashford, N.J., Martin Stanton, H.P., and Moore, C.A. (1997), Airport Operations, McGraw Hill, London, UK.

Ashford, N.J. and Wright, P.H. (1992), Airport Engineering, Wiley, Chichester, UK.

BAA (1997), BAA Planning Guidelines (Calculations), Group Planning, BAA, Gatwick, UK

Blow, C.J. (1996), Airport Terminals, Butterworth-Heinemann, Oxford, UK

Davies, Langdon \& Everest Consultancy Group (2000), Spon's architects and builders price book 2001, E and F.N. Spon, London, UK.

De Neufville, R and Odoni, A. (2003), Airport Systems: Planning, Design and Management. McGraw-Hill, New York

De Neufville, R and Odoni, A. (1992), Passenger Terminal Design. Transportation Research A, 26A, 27-35. 
DfT (2000), Air Traffic Forecasts for the United Kingdom 2000. Department for Transport, London.

DfT (2003), The Future of Air Transport. Department for Transport, Stationery Office, London

Doganis, R. (2001), The airline business in the $21^{\text {st }}$ century, Routledge, London, UK.

EMA (2003), Summer 2003 Passenger Schedule, Nottingham East Midlands Airport, UK.

FAA (1988), Planning and Design Guidelines for Airport Terminal Facilities, AC 150/5360-

13, Federal Aviation Administration, US Department of Transportation, USA

Hanlon, J.P. (1999), Global Airlines, Butterworth-Heinemann, Oxford, UK.

Horonjeff, R and McKelvey, F.X. (1994), Planning and Design of Airports, McGraw-Hill, New York.

IATA (1985), Airport Development Reference Manual, International Air Transport Association, Montreal

OAG (2002), Worldwide Airport Traffic Schedules, Official Airline Guide.

RATI (2004), Regional Air Transport Intelligence, Reed Business Information, London, UK. Available from http://www.rati.com, last accessed 2/3/04.

Wells, A.T. (2000), Airport Planning and Management, McGraw-Hill, USA. 